\title{
Primary melanoma of the small bowel revealed by gastrointestinal bleeding: a case report
}

\author{
B. Ait $\operatorname{dir}^{1 *}$, A. Riany ${ }^{1}$, A. Jahid ${ }^{2}$ and B. Chad ${ }^{1}$
}

\begin{abstract}
Background: Primary melanoma of the small bowel is extremely rare. Only a limited number of cases have been described in the literature. Mostly, the small intestine is affected by metastatic tumors of other primary lesions, especially cutaneous.

Case presentation: We report the case of a 75 -year-old North African woman with a small bowel melanoma. The diagnosis was made by histological examination and immunohistochemical profile matching after a segmental small bowel resection. Postoperative investigations looking for cutaneous, gastrointestinal or ocular primary lesions found no abnormalities.

Conclusions: The diagnosis of primary small bowel melanoma can be retained although it remains difficult to exclude the possibility of metastatic melanoma.
\end{abstract}

Keywords: Intestinal melanoma, Primary melanoma of the small bowel, Gastrointestinal bleeding

\section{Background}

Melanoma is a malignant tumor developed from melanocytes which are usually located in the skin, the eye's choroid, the meninges, and the anal margin. Melanoma of the gastrointestinal tract represent 1 to $3 \%$ of the digestive cancers $[1,2]$, it is essentially a metastasis of a cutaneous, ocular, or anal primary lesion [3]. Primary melanoma of the small bowel is exceptional, only few cases have been reported in the literature due to the difficulty in excluding another primary cancer $[2,4]$. Regardless of its primary or secondary character, intestinal melanoma remains more aggressive with a poor prognosis compared to other nondigestive locations. The median overall survival is 4 to 6 months with a survival rate of less than $10 \%$ at 5 years $[3,5]$.

With regard to therapeutic approach, there is no real consensus in the curative treatment of primary melanoma of the gastrointestinal tract. Surgery remains an essential approach for this disease, since effective adjuvant systemic therapies are without benefit for overall survival [6]. The

\footnotetext{
* Correspondence: aitidirbadr@gmail.com

${ }^{1}$ Surgery Unit B, Ibn Sina University Hospital, Rabat, Morocco

Full list of author information is available at the end of the article
}

optimal surgical technique consists of a carcinologic resection of the tumor.

\section{Case presentation}

We report the case of a 75-year-old North African woman with no notable medical history, admitted for pelvic pain lasting for the last 4 months and unrelieved by analgesics; the transit was undisturbed. The symptoms were aggravated by melena and asthenia that motivated the medical consultation. A clinical examination at admission found a patient with a stable hemodynamic status, an abdominal examination revealed a palpable and mobile pelvic mass. Laboratory tests showed a hypochromic and microcytic anemia with low hemoglobin and hematocrit levels rating at $7.3 \mathrm{~g} / \mathrm{dL}$ and $21 \%$. An abdominal computed tomography $(\mathrm{CT})$ scan showed a large pelvic mass measuring $11 \times 9 \mathrm{~cm}$ involving the distal small bowel loops, the bladder dome, and the uterine body without peritoneal effusion (Fig. 1). After primary care, our patient underwent an exploratory laparotomy. The intraoperative finding was a brownish pseudoaneurysmal mass of the small bowel located $80 \mathrm{~cm}$ from the Treitz's angle; this mass was invading the bladder dome and the left ovary and closely adhering to the uterus (Fig. 2). Limited 


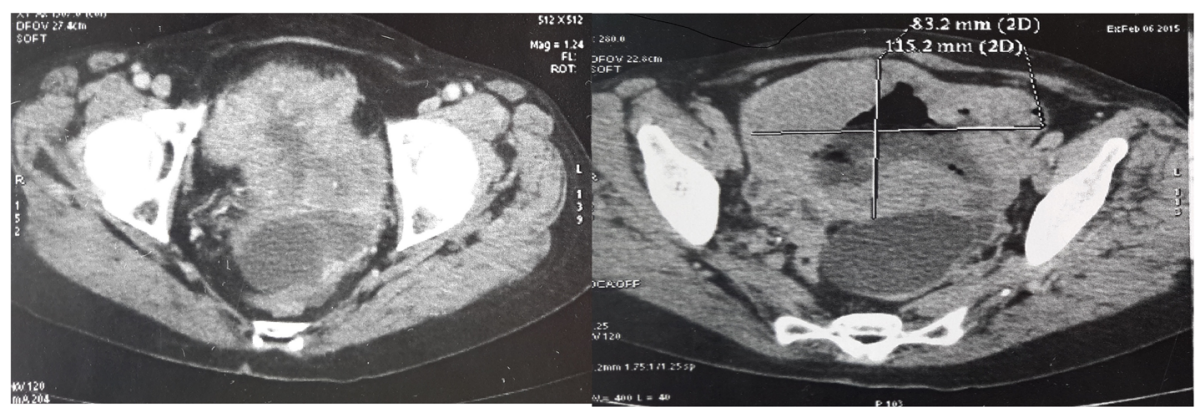

Fig. 1 Computed tomography scan showing a pelvic mass measuring $11 \times 9 \mathrm{~cm}$ involving the distal small bowel loops, the bladder dome, and the uterine body without peritoneal effusion

small bowel resection with $10 \mathrm{~cm}$ margins on both sides of the tumor extended to the left annexes and to a portion of the bladder with end-to-end anastomosis was achieved. The postoperative management was uneventful and our patient was discharged on day 6 . The surgical specimen was $18 \mathrm{~cm}$ in length and included a black solid tumor with exophytic growth infiltrating the small bowel wall until the mucosa (Fig. 3). A histological examination revealed a malignant proliferation of large cells with prominent round nuclei and a cytoplasm with eosinophilic spots or the seat of melanin pigments. Tumor necrosis was estimated at $30 \%$, the rest of the ileum was the seat of chronic ileitis (Fig. 4). The immunohistochemical profile showed an intense and diffuse cytoplasmic positivity for HMB-45 antigens and for PS-100, suggesting a malignant melanoma (Figs. 5 and 6). An etiological investigation in search of a primary tumor of the small bowel melanoma was negative, an anoscopy, examinations of eyes and skin with multiple cutaneous biopsies were performed without finding any melanoma lesion.

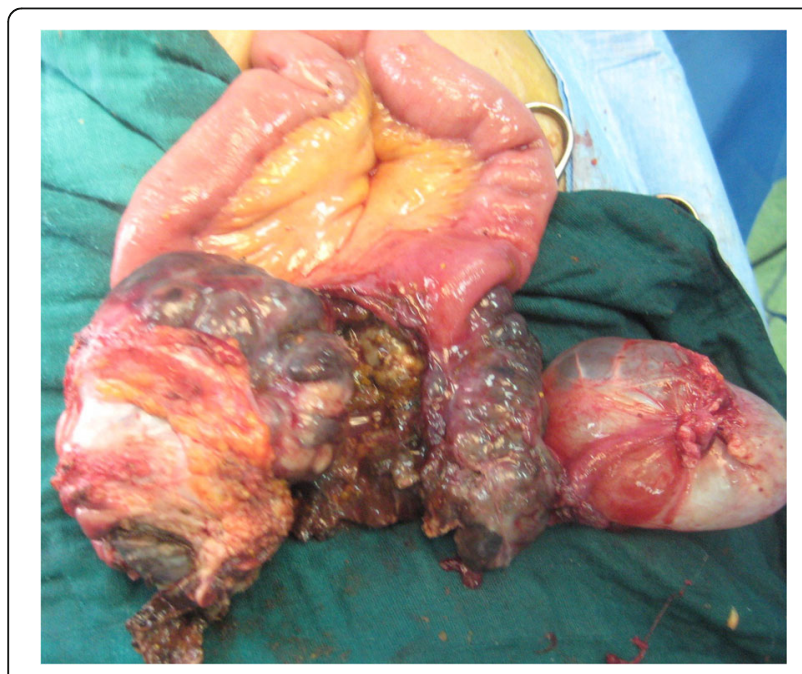

Fig. 2 Intraoperative finding revealing a pseudoaneurysmal tumor of the small intestine involving the left ovary

\section{Discussion}

Melanoma develops in the melanocytes, which are dendritic cells present in the skin, the eye, and the epithelium of the nasal cavity, oropharynx, anus, vagina, and urinary tract. In addition to these sites, it was proven by immunoperoxidase studies that melanocytes are present in Meckel's diverticulum $[7,8]$. Normally, the small intestine and the colon do not contain melanocytes. Embryologically, they arise from neural crest melanoblasts which migrate to the distal ileum through the umbilical-mesenteric canal $[7,9]$. They differentiate by amine precursor uptake and decarboxylation (APUD), and can undergo neoplastic transformation in noncutaneous sites [10]. According to this theory, the ileum is the most common site for the development of primary melanoma of the small intestine, although some authors still deny the existence of primary melanoma in the gastrointestinal tract. They argue that primary cutaneous tumors can regress before metastatic manifestations or they are too small to be identified by clinical and laboratory examinations [2]. Primary or secondary gastrointestinal melanoma is difficult to establish resulting in many controversies [11].The gastrointestinal

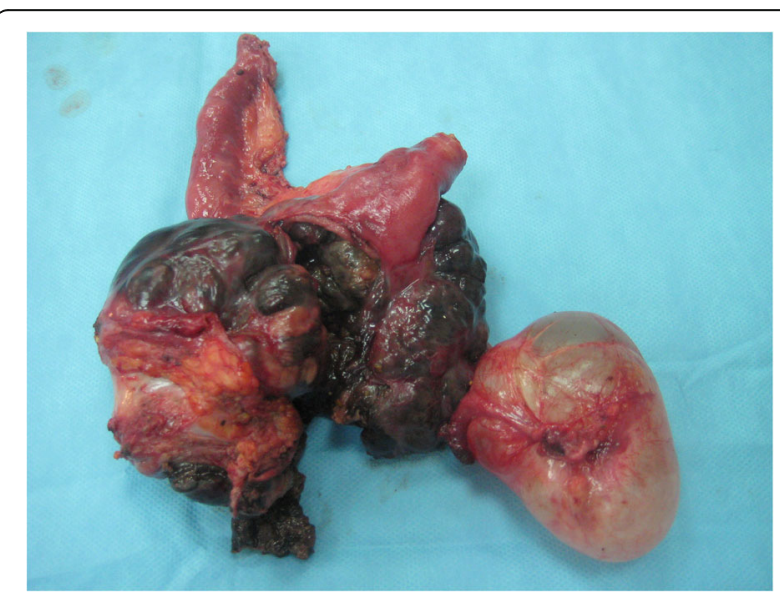

Fig. 3 Limited small bowel resection extended to the left annexes and to a portion of the bladder 


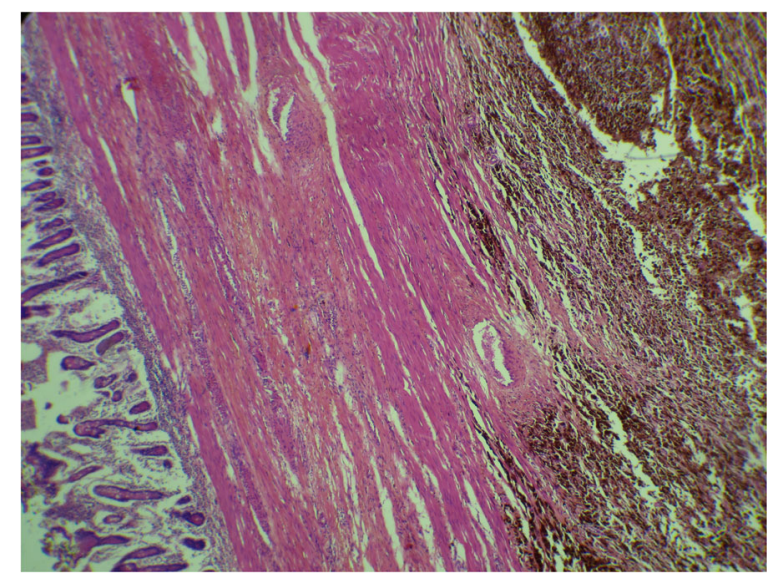

Fig. 4 Large tumoral malignant cell proliferation with melanin pigmentations infiltrating the small bowel wall. Hematoxylin and eosin, $\times 100$

tract is the most common site of cutaneous melanoma metastasis $[4,10]$. Usually asymptomatic, metastases are diagnosed at autopsy in $58 \%$ of patients with cutaneous melanoma [9], they may be clinically detected only after treatment of primary melanoma, or spontaneous regression [5], affecting primarily the small intestine, stomach, and colon $[4,12]$. However, some gastrointestinal melanomas remain undocumented and without evidence of a primary lesion, cutaneous or elsewhere, even after a thorough examination [13].The incidence of metastatic gastrointestinal melanoma of unknown primary origin is from 4 to $9 \%$ in case series [14]. In order to distinguish between primary and metastatic intestinal melanoma, Bender et al. were able to identify four different types of metastatic melanoma of the small intestine based solely on histopathological features: cavitary, infiltrating, eccentric, and polypoid [15]. Lymphocytic infiltrate with melanophages,

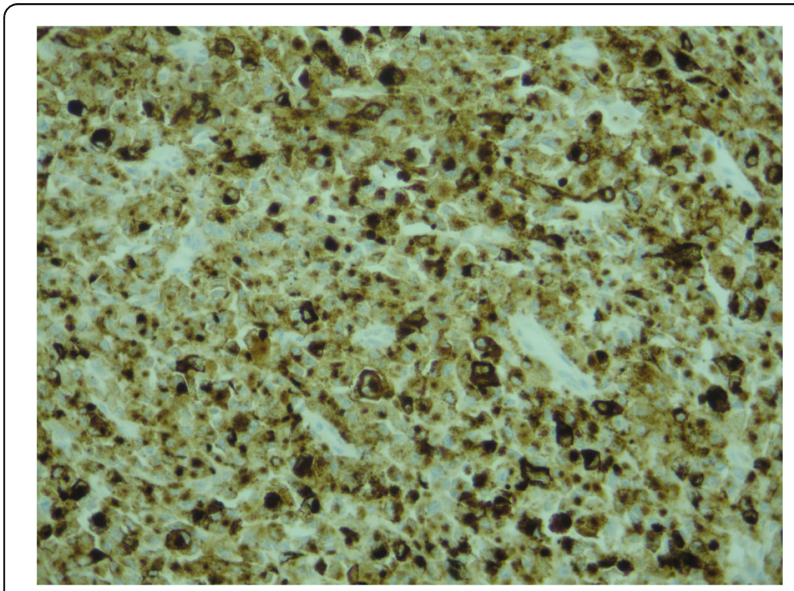

Fig. 5 Tumor cells are positive in immunohistochemical staining for $\mathrm{HMB}-45$

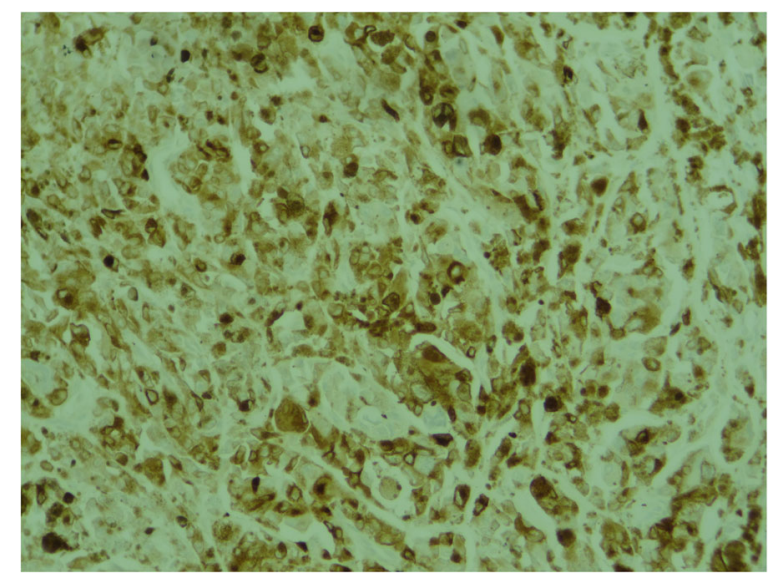

Fig. 6 Tumor cells are positive in immunohistochemical staining for S-100

restorative fibrosis, and a vascular proliferation present in the dermis are commonly seen in intestinal metastatic melanoma developed after spontaneous regression of the primary cutaneous lesion [6]. To make the diagnosis of primary malignant melanoma of the small intestine, other authors recommend excluding any history of melanoma in the other major sites. Sacks et al. established three diagnostic criteria: (1) single lesion, (2) no metastatic location other than in the regional lymph nodes, (3) relapse-free survival of more than 1 year after diagnosis [16].

In our case, histological study confirmed the diagnosis of intestinal melanoma with concordant immunohistochemical profile; our patient had no history of cutaneous melanoma, and etiological examination found no other melanoma lesion. At 1-year follow-up, clinical examination and abdominal CT scan control showed no intraperitoneal signs of recurrence. The diagnosis of a primary malignant melanoma of the small bowel has been established.

Adjuvant systemic therapy has a limited role, different chemotherapy regimens have been applied but the response rates were extremely low [6]. In our case, no adjuvant therapy was administered.

\section{Conclusions}

The diagnosis of primary intestinal melanoma can be confirmed based on the criteria described in the literature; however, early diagnosis and surgical resection are essential for improving the prognosis.

\section{Acknowledgements}

Not applicable.

Funding

No funding involved.

Availability of data and materials Not applicable. 


\section{Authors' contributions}

$A B$ drafted and edited the manuscript. RA contributed to the writing of the manuscript. AJ drafted the pathology section. CB critically revised the manuscript. All authors read and approved the final manuscript.

\section{Competing interests}

The authors declare that they have no competing interests.

\section{Consent for publication}

Written informed consent was obtained from the patient for publication of this manuscript and any accompanying images. A copy of the written consent is available for review by the Editor-in-Chief of this journal.

\section{Ethics approval and consent to participate}

Not applicable.

\section{Author details}

'Surgery Unit B, Ibn Sina University Hospital, Rabat, Morocco. ${ }^{2}$ Pathology

Unit, Ibn Sina University Hospital, Rabat, Morocco.

Received: 27 August 2016 Accepted: 24 October 2016

Published online: 01 December 2016

\section{References}

1. Elsayed AM, Albahra M, Nzeako UC, Sobin LH. Malignant melanomas in the small intestine: a study of 103 patients. Am J Gastroenterol. 1996;91(5):1001-6.

2. Atmatzidis KS, Pavlidis TE, Papaziogas BT, Papaziogas TB. Primary malignant melanoma of the small intestine: report of a case. Surg Today. 2002;32:831-3.

3. Chang AE, Karnell LH, Menck HR. The National Cancer Data Base report on cutaneous and noncutaneous melanoma: a summary of 84,836 cases from the past decade. The American College of Surgeons Commission on Cancer and the American Cancer Society. Cancer. 1998;83:1664-78.

4. Kadivar TF, Vanek WW, Krishnan EU. Primary malignant melanoma of the small bowel: a case study. Am Surg. 1992;58(7):418-22.

5. Schuchter LM, Green R, Fraker D. Primary and metastatic diseases in malignant melanoma of the gastrointestinal tract. Curr Opin Oncol. 2000;12:181-5.

6. Lens M, Bataille V, Krivokapic Z. Melanoma of the small intestine. Lancet 2009;10:516-21.

7. Amar A, Jougon J, Edouard A, Laban P, Marry JP, Hillion G. Primary malignant melanoma of the small intestine. Gastroenterol Clin Biol. 1991;16(4):365-7.

8. Bloch T, Tejada E, Brodhecker C. Malignant melanoma in Meckel's diverticulum. Am J Clin Pathol. 1986;86:231-4.

9. DasGupta TK, Brasfield RD. Metastatic melanoma of the gastrointestinal tract. Arch Surg. 1964;88:969-73.

10. Krüger $S$, Noack F, Blöchle $C$, Feller AC. Primary malignant melanoma of the small bowel: a case report and review of the literature. Tumori. 2004:91(1):73-6.

11. Poggi SH, Madison JF, Hwu WJ, Bayar S, Salem RR. Colonic melanoma, primary or regressed primary. J Clin Gastroenterol. 2000;30:441-4.

12. Avital $S$, Romaguera $R L$, Sands $L$, Marchetti F, Hellinger MD. Primary malignant melanoma of the right colon. Am Surg. 2004;70(7):649-51.

13. Woollons A, Derrick EK, Price ML, Darley CR. Gastrointestinal malignant melanoma. Int J Dermatol. 1997:36:129-31.

14. Manouras A, Genetzakis M, Lagoudianakis E, et al. Malignant gastrointestinal melanomas of unknown origin: should it be considered primary? World J Gastroenterol. 2007:13:4027-9.

15. Bender GN, Maglinte DD, McLarney JH, Rex D, Kelvin FM. Malignant melanoma: patterns of metastasis to the small bowel, reliability of imaging studies, and clinical relevance. Am J Gastroenterol. 2001;96(8):2392-400.

16. Sachs $D L$, Lowe $L$, Chang $A E$, et al. Do primary small intestinal melanomas exist? Report of a case. J Am Acad Dermatol. 1999;41:1042-4.

\section{Submit your next manuscript to BioMed Central and we will help you at every step:}

- We accept pre-submission inquiries

- Our selector tool helps you to find the most relevant journal

- We provide round the clock customer support

- Convenient online submission

- Thorough peer review

- Inclusion in PubMed and all major indexing services

- Maximum visibility for your research

Submit your manuscript at www.biomedcentral.com/submit 